\title{
SPATIO-TEMPORAL ANALYSIS OF HOUSE PRICE CONVERGENCE BASED ON A DEMOGRAPHICAL DISTANCE
}

\author{
Le MA ${ }^{1}$ and Chunlu LIU $2 \bowtie$ \\ ${ }^{1}$ School of Architecture and Built Environment, Deakin University, 1 Ghrenghap Street \\ Geelong, Geelong, Victoria 3220, Australia \\ ${ }^{2}$ School of Architecture and Built Environment, Deakin University, 1 Ghrenghap Street \\ Geelong, Geelong, Victoria 3220, Australia \\ E-mail: chunlu@deakin.edu.au
}

Received 13 January 2012; accepted 26 June 2012

\begin{abstract}
Convergences of house prices have been studied for over three decades, but yet have been confirmed because of spatial heterogeneity and autocorrelations in house prices. A spatio-temporal approach was recently proposed to address the spatial and temporal issues related to house prices. However, most previous studies placed the focus on the spatial heterogeneity and autocorrelations from geographical locations, which neglected other spatial factors. In order to overcome this shortfall, this research argued a demographical distance, constructed by demographical structure and housing market scales, to investigate the house price convergences in Australian capital cities. The results confirmed the house price levels in Canberra, Brisbane and Perth converged to the house price level in Sydney.
\end{abstract}

KEYWORDS: Spatio-temporal model; Demographical structures; Panel regression; House price convergence

REFERENCE to this paper should be made as follows: Ma, L. and Liu, C. (2013) Spatiotemporal analysis of house price convergence based on a demographical distance, International Journal of Strategic Property Management, 17(3), pp. 263-277.

\section{INTRODUCTION}

Studies into house price convergences are to investigate the equilibrium of house prices in the long run. It addresses the question of whether house prices in different regions can move towards one or several steady states. A typical housing market is composed of a segmented series but also interconnected submarkets (Meen, 1996). This proposition about house price ripple effects and segmentations then highlighted the concern about the house price convergence. Because of the presence of unit roots in house price levels, investigation of the house price convergences are based on the existence of consistent gaps or different ratios between regional house prices and a benchmark, such as a national house price or the house price in a dominant region. If the different ratio convergence exists, the regional house prices in a nation will move towards a steady state, which can be reflected by a vector.

A study into the long-run equilibrium relationships or convergence between regional housing prices has been undertaken (MacDonald and Taylor, 1993). However, the findings failed to prove regional house prices in the UK converging to a steady state. Drake (1995) conducted a formal test into the convergence of UK regional house prices. Once again, no strong evidence was generated to support the 
convergence of house price different ratios. A time-series testing method, so-called "unit root test", has been widely used to investigate the convergence of house price ratios. Cook (2003) argued the limitation of this method led to the failure of uncovering the existence of convergence. Alternatively, Cook (2003) proposed an asymmetric unit root test to capture the convergence of house price different ratios. The pair-wise convergences of regional house price ratios in the UK were investigated by using the asymmetric method, although the detection of convergence was not strongly supported by the research evidence.

It is accepted that variables in a time-series regression model are required to be stationary, because non-stationary variables may cause the results to be unreliable since house prices are not stationary at levels. This implies the possibility of non-stationary for the house price different ratios and therefore, convergence is difficult to detect using time-series methods. Holmes (2007) proposed an innovative approach to investigate the price ratio convergence by employing the unit root tests within a panel regression framework. This panel unit root model considered the heterogeneity in a steady state as well as in the regional speeds of convergence. In the same study, the panel unit root was applied to UK regional house prices, where the findings concluded the panel regression model was more powerful than a purely time-series model (Holmes, 2007). It was also demonstrated that the convergences of house price ratios were detected in most regions of the UK. The panel unit root tests were subsequently improved by implementing the first principal component (Holmes and Grimes, 2008).

Previous studies have employed time-series and panel regression models to identify the convergence for housing price ratios across regions although few studies have addressed the spatial correlations of house prices when they accessed the house price convergence. Therefore, this research will add to the literature by testing the house price convergence with a spatial correlation. In addition to that, a new spatial measure between different housing markets is also proposed. General impulse response functions are also employed to forecast house price levels. The balance of this paper is organised as follows: the second section reviews the literature related to spatio-temporal analysis and the extension of distance. The third section illustrates the theories and methodologies of the spatio-temporal model for house price convergence, demographical distance and general impulse response functions. The fourth section describes the housing markets and demographical structures in Australia capital cities. The fifth section reports the empirical results of house price convergence in the Australian capital cities. The final section concludes.

\section{LITERATURE REVIEW}

The spatio-temporal analysis methods can address the effects of spatial heterogeneity and autocorrelations. The following paragraphs reviews previous studies into the house price with the spatio-temporal methods, followed by a discussion of the extension of spatial measurement based on the related literature.

\subsection{Spatio-temporal analysis of house prices}

Spatio-temporal analysis methods have been increasingly used in studies into house prices. An approach built on the framework of the repeat-sales model was employed to address the spatial and temporal effects on house prices (Quercia et al., 2000). The traditional repeatsales model was improved by incorporating spatial considerations with seemingly unrelated regression (SUR) estimated method. The improved spatio-temporal model resulted in a comprehensive explanation of house price appreciations, confirming appreciations of house prices were influenced by the prices in nearby properties. Another empirical study employed spatial autoregressive model to evaluate the prices of foreclosed properties, arguing that in addition to the time that properties stay 
on the market, the physical condition, occupancy status and neighbourhood characteristics contributed to price valuations (Clauretie and Daneshvary, 2009). The same study also demonstrated that ignoring the characteristics of spatial dependence and the time spent on the market by foreclosed properties could lead to depreciations in prices. The spatio-temporal vector autoregression model was also used to analyse the effects of fundamental economic innovations on house prices in the western United States (Kuethe and Pede, 2009). Based on the spatio-temporal vector autoregression model, bivariate Granger causality tests and impulse response functions were adopted to illustrate the relationship between house price movements and the economic factors across states. Holly et al. (2011) used a spatio-temporal vector error correction model to investigate the house price diffusion in the UK. The housing market in London was viewed as a dominant housing market for the regional housing markets in the UK. Interestingly, the housing market in New York was also implemented as a benchmark in the UK regional housing markets. The diffusion patterns of the regional house prices in the UK were illustrated by using the impulse response functions. According to previous studies, the inherent advantages of the spatio-temporal methods are the ability to reflect both the spatial and temporal correlations between house prices. However, most of the previous studies built the spatial measurement on geographical distances, which may still neglect certain important spatial information related to house prices in different regions.

\subsection{Extension of spatial distance}

How to measure the potential interaction between two spatial units is viewed as a controversial issue in spatial econometrics (Anselin, 1988). One original suggestion was to use a combination of distance measures and the relative length of the common border between two spatial units. However, Anselin (1988) also demonstrated the distance based on this method tended to be less meaningful since the notions of boundary length and area were largely artificial as the spatial interactions were determined by factors which have little to do with the spatial configuration of boundaries on a physical map. An economic distance was proposed and applied to a spatial model, arguing that an economic distance could be constructed from information regarding this economic distance, but it varied across individual studies (Conley, 1999). Elhorst (2003) argued that an observation associated with a specific location was dependent on observations in other regions, mainly because that distance affected economic behaviour. Pesaran et al. (2004) used the trade share between pairs of countries to construct a theoretical distance. The trade-share based distance was then applied to a global macroeconomic model to indicate the effects from foreign countries on domestic countries. Krugman (2011) also suggested that spatial models, which focused more on the tangible causes of spatial interconnections of economic activities rather than on intangible information spillovers, were less relevant in describing economies.

The discussions regarding the spatial measurement between different housing markets have been demonstrated by several studies. Poterba et al. (1991) studied the explanations for United States house price movements in three empirical tests, namely changes in construction costs, changes in the real after-tax cost of homeownership and changes in demographic factors. It was demonstrated that demographic change provided an important explanation for the decrease in house prices in the 1980s. The statistical results confirmed the age structure of the population could predict a relationship for the United States as a whole between the level of real house prices and housing demand. Bourassa and Hendershott (1995) examined the fundamental forces that drove real house prices in six Australian cities. The findings suggested that real house prices could be influenced by the increase in incomes, and the growth of population generated by overseas migration. The tight correlations between age structures of population 
and house prices were also confirmed by another study (Rodda and Patrabansh, 2007). It was suggested that the price of houses for homeowners of different ages could appreciate at various rates, with the houses of elderly homeowners appreciating at slower rates relative to the average rates of the local markets, or relative to the appreciation rates of houses of middle aged homeowners. Since the age structure of population influences house prices significantly, this research proposes a demographical distance to measure the spatial interconnections between house prices in different cities. Moreover, Sydney is recognised as the dominant city among the Australian capital cities. The following sections illustrate the spatio-temporal analysis methodologies to investigate the house price convergences and the construction of demographical distance.

\section{SPATIO-TEMPORAL ANALYSIS OF HOUSE PRICE CONVERGENCE}

The conception model of house price convergence is based on a framework of vector error correction models (VECM), which is expressed as follows:

$$
\Delta d_{i t}=\alpha_{i}+\beta_{i} d_{i, t-1}+\sum_{s=1}^{q} \rho_{i, t-s} \Delta d_{i, t-s}+u_{i t},
$$

where: $d_{i t}=p_{i t}-p_{0 t}$ denotes the house price difference ratio of a house price $p_{i t}$ to a benchmark price $p_{0 t} ; p$ denotes the logarithm values of house prices. Subscripts $i$ and $t$ stand for region and time, respectively. $\Delta d_{i t}$ is defined by $d_{i t}-d_{i, t-1}$. Symbols $\alpha_{i}, \beta_{i}$ and $\rho_{i, t-s}$ are estimators, while $u_{i t}$ indicates disturbances. A significant negative estimate of $\beta_{i}$ shows the stationarity of series $d_{i}$, which implies house prices in region $i$ will converge to the benchmark price level in a long run perspective. However, the effects of the spatial information and regional heterogeneity cannot be completely uncovered by the former processes. In order to overcome these weaknesses, this research improves the VECM model by incorporating spatial dependence into a panel regression model with fixed effects to investigate the convergence of house prices. Furthermore, instead of geographical distance, this research utilises a distance defined by demographical structures and the scale of market developments to construct spatial dependence.

\subsection{Development of the spatio-temporal model for house price convergence}

Denoting $p_{0 t}$ as the house price in the dominant region, where a shock in the price movements is assumed to occur first, at time $t$, the convergence model with spatial dependence specification is given by

$$
\Delta p_{0 t}=\alpha_{0}+\beta_{0} p_{0, t-1}+\rho_{0} \Delta p_{0, t-1}+\gamma_{0} \Delta p_{0, t-1}^{w}+u_{0}(2)
$$

for the dominant region and

$$
\begin{aligned}
& \Delta d_{i t}=\alpha_{i}+\beta_{i} d_{i, t-1}+\rho_{i} \Delta d_{i, t-1}+\gamma_{i} \Delta p_{i, t-1}^{w}+u_{i t}, \\
& \Delta p_{i t}-\Delta p_{0 t}=\alpha_{i}+\beta_{i}\left(p_{i, t-1}-p_{0, t-1}\right)+ \\
& \rho_{i}\left(\Delta p_{i, t-1}-\Delta p_{0, t-1}\right)+\gamma_{i} \Delta p_{i, t-1}^{w}+u_{i t}
\end{aligned}
$$

for the other cities. The term $\Delta p_{t}=p_{t}-p_{t-1}$ indicates the temporal increase of house prices. The term $\Delta p_{i t}^{w}$ is calculated as $\Delta p_{i t}^{w}=\sum_{i \neq j} w_{i j, t} \Delta p_{j t}$, indicating the spatial effects from neighbouring regions. $w_{i j, t}$ is the spatial weight of region $i$ in the regarding to region $j$, the detail of which is illustrated in the following section. The negative and significant estimates of $\beta$ demonstrate that the proportional convergence exists across regions. In order to eliminate the effects of series correlations across the cities, the SUR method is also applied on the panel system.

In order to simulate and forecast regional housing market performances, Eqs. (2) and (3) can also be recognised as a system of equations that need to be solved simultaneously, expressed as follows:

$$
\Delta P_{t}=\mathrm{A}+\mathrm{B} P_{t-1}+\Gamma \Delta P_{t-1}+E \Delta P_{t}+U_{t},
$$

where: $P_{t}=\left(p_{0 t}, p_{1 t}, p_{N t}\right)^{\prime}, \mathrm{A}=\left(\alpha_{0}, \alpha_{1}, \ldots, \alpha_{N}\right)^{\prime}$, $U_{t}=\left(u_{0 t}, u_{1 t}, \ldots, u_{N t}\right)^{\prime}$,

$$
\mathrm{B}=\left(\begin{array}{cccc}
\beta_{0} & 0 & \ldots & 0 \\
-\beta_{1} & \beta_{1} & \ldots & 0 \\
\vdots & \vdots & \ddots & \vdots \\
-\beta_{N} & 0 & \cdots & \beta_{N}
\end{array}\right), E=\left(\begin{array}{cccc}
0 & 0 & \ldots & 0 \\
1 & 0 & \ldots & 0 \\
\vdots & \vdots & \ddots & \vdots \\
1 & 0 & \cdots & 0
\end{array}\right),
$$




$$
\begin{aligned}
& \Gamma=\left(\begin{array}{cccc}
\rho_{0} & 0 & \ldots & 0 \\
-\rho_{1} & \rho_{1} & \ldots & 0 \\
\vdots & \vdots & \ddots & \vdots \\
-\rho_{N} & 0 & \cdots & \rho_{N}
\end{array}\right)+\left(\begin{array}{c}
\gamma_{1} W_{1}^{\prime} \\
\gamma_{2} W_{2}^{\prime} \\
\vdots \\
\gamma_{N} W_{N}^{\prime}
\end{array}\right) \text { and } \\
& W_{i}=\left(w_{i 1, t}, w_{i 2, t}, \ldots, w_{i N, t}\right)^{\prime} .
\end{aligned}
$$

Eq. (4) presents a system of error correcting vector autoregressions with spatial lags in the regional house prices. This model can also be written as a spatio-temporal VAR model, expressed as follows:

$$
(I-E) P_{t}=\mathrm{A}+\Pi_{1} P_{t-1}+\Pi_{2} P_{t-2}+U_{t},
$$

where: $\Pi_{1}=\left(\mathrm{B}+\Gamma+I_{N}-E\right), \Pi_{2}=-\Gamma$ and $I_{N}$ denotes the $N \times N$ identity matrix. The temporal dependence of regional house prices is captured by the coefficient matrices $\Pi_{1}$ and $\Pi_{2}$. The spatial dependence is captured by the covariance of the error term $U_{t}, \operatorname{Cov}\left(u_{i t}, u_{j t}\right)$ with $i \neq j$. The temporal coefficients $\Pi_{1}$ and $\Pi_{2}$ are affected by the spatial dependence of the regional house prices. Those spatial dependences are constrained by the non zero values of $w_{i j}$. Subsequently, the impulse response functions based on Eq. (4) can be used to interpret the temporary and spatial interconnections among regional house prices.

Although the spatial effects were considered in the aforementioned model to analyse the regional convergence of house prices, the model is still confined to interpreting the converging status in discrete time periods. By applying panel data regression techniques we can capture the house prices' converging characteristics for a continuous long run period. As can be observed from Eq. (3), the estimated constant coefficients and the coefficients of the house prices indicate the steady states and the converging speed rates. Moreover, the coefficients of the temporal lags and the spatial lags explain the magnitudes of the regional house price growth influenced by the temporal and spatial effects. By using different pre-assumptions, it is possible to catalogue the model into three types, namely the regional absolute convergence model, the regional conditional convergence model and the regional club convergence model.

\subsection{Construction of demographical spatial weights}

Using a demographic distance, house prices can be recognised as spatial autocorrelation, if a common shock in house price is able to create similar effects in regions with a short demographical distance but distinct effects in regions that are demographically far from each other. Azomahou et al. (2009) first studied the spatial persistence of demographic shocks and economic growth. It is suggested that per capita income growth can be significantly affected by the variation in demographical distance. This research adopts the theory of a demographical distance proposed by Azomahou et al. (2009) to analyse house price convergences among the Australian capital cities. The demographical distance is construced by the logarithm values of the estimated age-structured population, which are the populations of people aging from 0 to 14,15 to 64 , and over 64 , of each Australian region. The logarithm values of population for age $0-14,15-64$ and $65+$, in a region $i$ at period $t$ is denoted as demo 14 , $d e m o_{i t}^{15 t o 64}$ and $d e m o_{i t}^{65}$, respectively. The demographical distance between regions $i$ and $j, d_{i j, t}^{\text {demo }}$, is constructed by the Euclidean distance with the three artificial location spots. The calculation of the demographic distance is expressed as follows:

$$
d_{i j, t}^{d e m o}=\left[\begin{array}{l}
\left(\text { demo }_{i t}^{14}-\text { demo }_{j t}^{14}\right)^{2}+ \\
\left(\text { demo }_{i t}^{15 t o 64}-d e m o_{j t}^{15 t o 64}\right)^{2}+ \\
\left(\text { demo }_{i t}^{65}-\text { demo }_{j t}^{65}\right)^{2}
\end{array}\right]^{\frac{1}{2}}
$$

It is supposed that the degree of an interconnection between two cities should have a negative relationship with the distance. That means cities with similar demographic structures may correlate with each other tightly. Hence, the demographical spatial weight based on the demographical distance will correlate with the demographical distance negatively, 
namely $w_{i j, t}^{\text {demo }}=f\left(\frac{1}{d_{i j, t}^{\text {demo }}}\right)$. Accordingly, a demographical spatial weight is calculated using the reverse of the distance, which means that the strongest effects are caused by the closet neighbours in the perspective of demographical distance.

As well as the demographical distances, the developing sizes of the housing markets may also be taken into account for the spatial effects. Market scales are recognised as an important indicator representing the spatial information of the regional markets. It is expected that the neighbouring markets with relatively large scales should result in more significant spatial effects on the local housing market than those with smaller scales. Bearing this in mind, this research uses number of new dwelling (nod) to stand for the housing market developing scales. The distance described above is combined with the market scales to propose a demographical spatial weight. The calculation of the weights is expressed as follows:

$$
w_{i j, t}^{D H}=\frac{1}{d_{i j}^{\text {demo }}} \times \frac{\operatorname{nod}_{j t}}{\operatorname{nod}_{i t}+\operatorname{nod}_{j t}} .
$$

\subsection{Impulse response functions}

Impulse response functions are widely used to study the effects of policy through VAR in the traditional econometrics field. The impulse response of the VAR indicates the dynamic effects on each variable when a shock is injected into the system, and this is termed as innovation. Accordingly, a system can be characterised by plotting the impulse response functions (Greene, 2002). The impulse response of Spatio-temporal VAR may be used to simulate the spatial-temporal dynamic effects of innovations on variables. However, it is more complex than in VAR because shocks propagate across cities as well as over time (Beenstock and Felsenstein, 2007). Denote $I$ as an $8 \times 8$ identical matrix, $\Gamma=B+C W$, and $L$ as the lagged operator. Eq. (4) can be rewritten as:

$$
\begin{aligned}
& (I-\Gamma L) \Delta P_{t}=D_{t}, \\
& \Delta P_{t}=(I-\Gamma L)^{-1} D_{t} .
\end{aligned}
$$

Since $\Gamma$ is dependent upon $W$, the response of the Spatio-temporal VAR under an innovation in $D$ will depend upon the spatial lag coefficients, $C$. In the Spatio-temporal VAR construct, a given shock affects the house price in the same region directly, while influencing the house prices in other cities through the spatial lag terms. Therefore, the shock of the house price in one city is transmitted to the neighbouring housing markets in the following period, weighted by $W$. The variance-covariance is expressed as follows:

$$
\Sigma=E\left(\varepsilon_{i} \varepsilon_{j}^{\prime}\right)=\left[\begin{array}{cccc}
\sigma_{11}^{2} & \sigma_{12}^{2} & \cdots & \sigma_{1 N}^{2} \\
\sigma_{21}^{2} & \sigma_{22}^{2} & \cdots & \sigma_{2 N}^{2} \\
\cdots & \cdots & \ddots & \cdots \\
\sigma_{N 1}^{2} & \sigma_{N 2}^{2} & \cdots & \sigma_{N N}^{2}
\end{array}\right],
$$

where: $\sigma_{i j}^{2}=\operatorname{cov}\left(\delta_{i t}, \delta_{j t}\right)$; and $g_{i}$ is an $8 \times 1$ vector with a unit in the $i^{\text {th }}$ element and zero in the other. The regional house price dynamics in the forecasting period can be derived from the generalised impulse response function (Pesaran and Shin, 1998) as follows:

$$
\Delta \widehat{p}_{i s}=\frac{\Psi_{s} \Sigma g_{s}}{\sigma_{i j}}, \Psi_{s}=\Gamma \Psi_{s-1} \text {, with } \Psi_{0}=I_{8} \cdot(9)
$$

\section{CORRELATED INFORMATION IN AUSTRALIA}

\subsection{Demographic structures in Australian capital cities}

"Australian Demographic Statistics" is published quarterly by the Australian Bureau of Statistics (ABS, 2011a). It includes the population statistics on births, deaths and overseas and interstate migration. It contains estimations of the population of Australia and states and territories by age groups and major population regions. For each state and territory, over half of the population is resident in the capital cities. The annual age group structures of the Australian states and Territories were estimated based on the quarterly data on the estimations for the resident population of 
Table 1. Average annual demographic structures for Australia: 1993-2010

\begin{tabular}{|c|c|c|c|c|c|c|c|c|}
\hline \multicolumn{9}{|c|}{ Population distributions } \\
\hline Age & NSW & Vic & Qld & SA & WA & Tas & NT & $\mathrm{ACT}$ \\
\hline 0 to 14 & $1,323,080$ & 963,377 & 784,814 & 292,752 & 403,868 & 100,293 & 50,491 & 65,051 \\
\hline 15 to 64 & $4,386,700$ & $3,289,574$ & $2,522,099$ & $1,011,339$ & $1,318,731$ & 314,159 & 139,304 & 229,790 \\
\hline Over 64 & 847,651 & 621,845 & 431,022 & 217,382 & 211,868 & 65,343 & 7,960 & 2,7327 \\
\hline \multicolumn{9}{|c|}{ Proportions of the age groups } \\
\hline 0 to 14 & $20.19 \%$ & $19.78 \%$ & $21.07 \%$ & $19.21 \%$ & $20.94 \%$ & $20.89 \%$ & $25.65 \%$ & $20.28 \%$ \\
\hline 15 to 64 & $66.78 \%$ & $67.32 \%$ & $67.39 \%$ & $66.24 \%$ & $68.01 \%$ & $65.35 \%$ & $70.36 \%$ & $71.36 \%$ \\
\hline Over 64 & $12.89 \%$ & $12.71 \%$ & $11.50 \%$ & $14.23 \%$ & $10.89 \%$ & $13.58 \%$ & $3.96 \%$ & $8.44 \%$ \\
\hline
\end{tabular}

Australia and its states and territories, published in the Australian Demographic Statistics (ABS, 2011a). The statistical results, from 1993 through to 2010 , were based on 2 main censuses of population and housing, which were carried out in 2001 and 2006. The resident population aged from 0 to over 85 were catalogued into three groups, namely age 0 to 14, age 15 to 64 and age over 65. Table 1 reports the average population in each state and territory from 1993 to 2010.

Huge differences were observed between the regional population numbers in the three age groups, confirming the Australian state population was distributed asymmetrically. Over $70 \%$ of the population was located in the eastern states of Australia, namely New South Wales, Victoria and Queensland. The population in the Northern Territory and Tasmania counted for less than $5 \%$ of the total Australian population. Compared to the huge differences in the regional population, the proportions that the age groups take out of the total state population appear not distinct in different states and territories. Northern Territory has the highest proportion of young people of 25.65\%, while South Australia has the lowest proportion at $19.21 \%$. The proportion of working people rages from $65.35 \%$ in Tasmania to 71.36\% in the Australia Capital Territory. The highest record of retired people was located in South Australia, while Northern Territory has the lowest proportion of the population aged over 65 .

\subsection{Developing scales of housing markets in the Australian capital cities}

The approved numbers of new houses in Australian capital cities are also published by the ABS. The numbers presented the monthly details of building work approved in the Australian capital cities (ABS, 2011b). Statistics of building work approved were compiled from permits issued by local government authorities and the other principal certifying authorities, contracts let by commonwealth, state, semigovernment and local government authorities and major building approvals in areas not subject to normal administrative approval. This set of data focuses on the scales of change for each capital city housing markets. The original monthly data was converted into quarterly data by summing the numbers every three months. Table 2 shows the basic statistics for the number of dwelling units during the observation period being analysed, including the quarterly average numbers, the maximums, the minimums and the standard deviations.

It was observed that Melbourne had the largest developing scale over the entire observation period. The average number of new houses in Melbourne was over 5129 in each quarter, followed by Perth and Sydney, which provided 3057 and 2741 new house approval numbers respectively. Brisbane was on a similar scale to Sydney, while Adelaide ranked the fifth with nearly half that of Brisbane. Melbourne also had the highest maximum, minimum and standard deviation. This suggests that fast and fluctuating developments 
Table 2. Statistics of the approved numbers of new houses in Australian capital cities

\begin{tabular}{lllllllll}
\hline & Adelaide & Brisbane & Canberra & Darwin & Hobart & Melbourne & Perth & Sydney \\
\hline Mean & 1338.75 & 2713.32 & 351.42 & 122.76 & 222.36 & 5129.24 & 3057.04 & 2741.47 \\
Minimum & 698 & 1646 & 179 & 46 & 87 & 2524 & 1826 & 1322 \\
Maximum & 2007 & 4024 & 627 & 289 & 365 & 7105 & 4127 & 4650 \\
Std. Dev. & 308.41 & 540.01 & 106.42 & 45.08 & 67.54 & 1030.91 & 560.69 & 928.62 \\
\hline
\end{tabular}

arose in Melbourne housing market scale. The housing market scales in Brisbane and Perth also increased quickly, although the increase degrees in these two cities were less than the increasing degrees in Melbourne and Sydney. The quarterly approved numbers of new houses in Hobart, Darwin and Canberra were very small, at 122, 222 and 351 respectively, indicating the smallest residential housing markets in these capital cities. The large differences in house market developing scales indicates the spatial heterogeneity of house price levels across cities may also depend on the scales of the markets. The spatial weights of house prices should be constructed using regional demographical distance and housing market distinctions.

\subsection{Demographical spatial weights for Australian house prices}

The demographical spatial weights were constructed based on the demographical age structures and the developing scales of housing markets in the Australian capital cities. This allows the demographical spatial weights to vary over the observation period. Table 3 presents the average values of the demographical spatial weights.

As observed from Table 3, Melbourne and Perth produced relatively higher spatial effects than the other cities, with Perth contributing the largest spatial weights to Adelaide and Canberra and Melbourne creating the largest spatial effects in Brisbane and Sydney. Sydney with a relatively larger scale did not always contribute the highest spatial weights, which could be counteracted by the long distance between Sydney and the other cities. Canberra, Hobart and Darwin supply relatively smaller weights, compared with the other cities. The introduction of the regional market developing scale enhances the spatial effects of cities with large scales, but shrinks the effects of cities with small scales. In other words, the importance of the developing scales of the housing market is emphasised by the weights.

This research tested the spatial autocorrelations between the house prices in Australian capital cities with these demographical spatial weights. Figure 1 gives Moran's I test results of the spatial autocorrelations for house prices in the Australian capital cities. The negative

Table 3. Average demographical spatial weights

\begin{tabular}{lllllllll}
\hline & Adelaide & Brisbane & Canberra & Darwin & Hobart & Melbourne & Perth & Sydney \\
\hline Adelaide & 0.0000 & 0.1367 & 0.0593 & 0.0368 & 0.0840 & 0.1074 & 0.4943 & 0.0815 \\
Brisbane & 0.1253 & 0.0000 & 0.0374 & 0.0258 & 0.0455 & 0.4074 & 0.1687 & 0.1900 \\
Canberra & 0.1240 & 0.0877 & 0.0000 & 0.2116 & 0.3041 & 0.0817 & 0.1198 & 0.0710 \\
Darwin & 0.1175 & 0.0930 & 0.3257 & 0.0000 & 0.1788 & 0.0887 & 0.1176 & 0.0787 \\
Hobart & 0.1689 & 0.1019 & 0.2922 & 0.1117 & 0.0000 & 0.0926 & 0.1542 & 0.0785 \\
Melbourne & 0.0880 & 0.3673 & 0.0313 & 0.0220 & 0.0370 & 0.0000 & 0.1105 & 0.3439 \\
Perth & 0.4570 & 0.1712 & 0.0521 & 0.0333 & 0.0697 & 0.1255 & 0.0000 & 0.0912 \\
Sydney & 0.0899 & 0.2317 & 0.0369 & 0.0265 & 0.0425 & 0.4637 & 0.1087 & 0.0000 \\
\hline
\end{tabular}




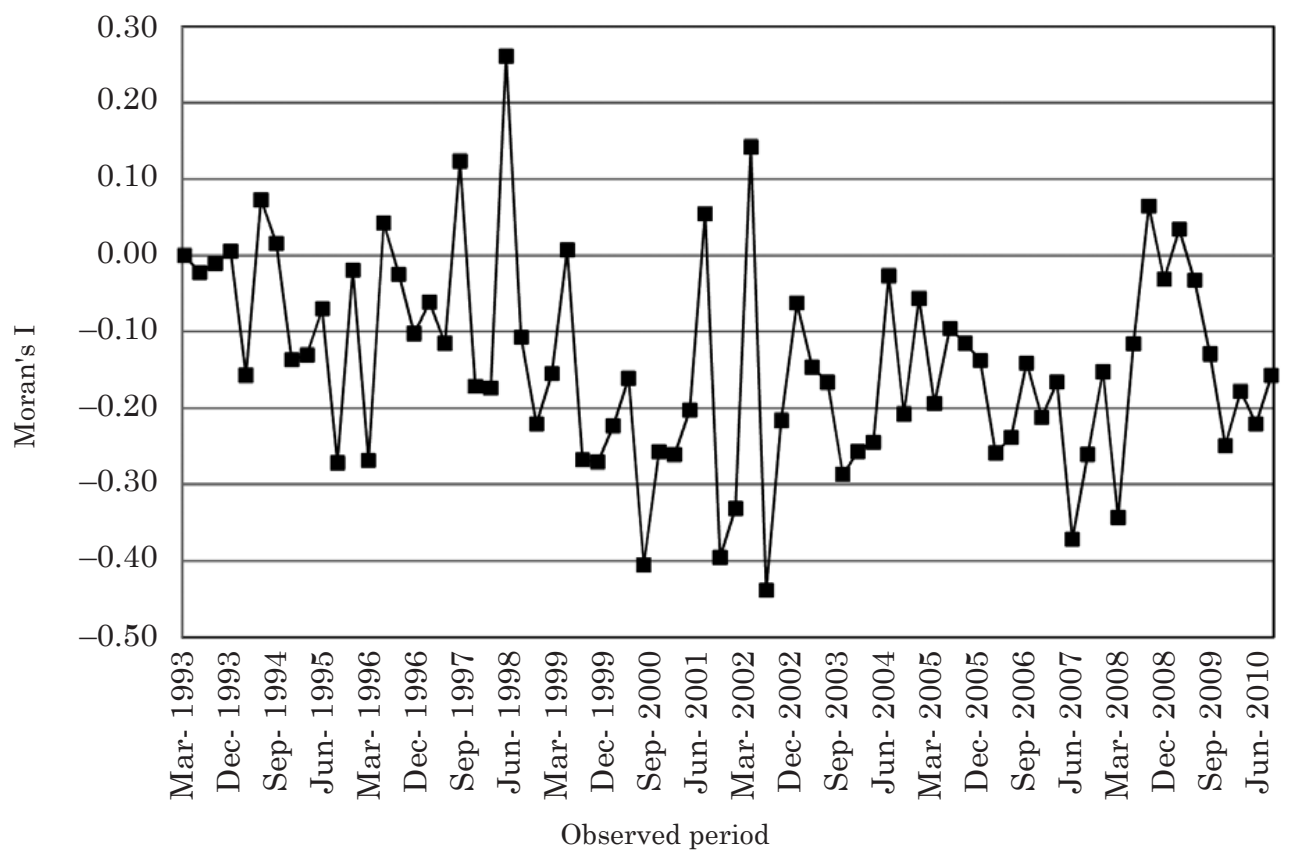

Figure 1. Spatial autocorrelation tests based on the demographical spatial weights

spatial autocorrelations were observed over the most of the observation period, confirming that the spatial effects on house prices in Australia shrink as the differences of the demographic structures between the cities become larger.

The values of the Moran's I dropped down from the beginning of the observation period and reached the first trough in late 1995, indicating that house prices at different spatial points, with regard to the demographic distance, moved dissimilarly from each other. The value of the Moran's I increased for the next three years, indicating a decrease in the degree of the dissimilarity between house prices. The change in the Australian tax system and the hosting of the Olympic Games may have had a national wide influence, which drove the house prices to move towards the same direction from 2000 to 2001. After that, the demographic factors seemed to dominate the spatial impacts on house prices in each city. The spatial autocorrelations between the cities became more significantly until 2007. The burst of the global financial crisis might again generate a huge influence on the house price movements for the whole country. A nationwide trend was visible among the house prices, when the degrees of dissimilarity began to fall in 2008 .

\section{HOUSE PRICE CONVERGENCE IN THE AUSTRALIAN CAPITAL CITIES}

This research used the spatio-temporal model to investigate the convergence of house prices in the Australian capital cities. The house price levels of Sydney were selected as the benchmark in this research. Previous research on the interconnections between Australian house prices showed that Sydney plays a role as an engine in influencing house price dynamics across the nation, suggesting research shows that house price in Sydney had a strong influence on the movements of house prices in other cities (Liu et al., 2008). The same study also demonstrated the house price in Sydney was not easily influenced by the movements of house prices in other capital cities. According to the dual characteristics of house price in Sydney, the Sydney housing market should be regarded as a dominant city among the Australian capital cities. 
Table 4. Estimates of the spatio-temporal convergence model

\begin{tabular}{lllll}
\hline Cities & \multicolumn{1}{c}{$\alpha$} & \multicolumn{1}{c}{$\beta$} & \multicolumn{1}{c}{$\rho$} & \multicolumn{1}{c}{$\gamma$} \\
\hline Adelaide & -0.0024 & -0.0281 & 0.1375 & 0.0681 \\
Brisbane & & $(0.0589)^{*}$ & $(0.1206)$ & $(0.5794)$ \\
& -0.0005 & -0.0352 & 0.2990 & 0.1241 \\
Canberra & & $(0.0136)^{* *}$ & $(0.0004)^{* *}$ & $(0.3712)$ \\
& -0.0021 & -0.0422 & 0.1038 & 0.1279 \\
Darwin & & $(0.0062)^{* *}$ & $(0.2277)$ & $(0.4827)$ \\
& 0.0035 & -0.0210 & 0.2121 & -0.5308 \\
Hobart & & $(0.1708)$ & $(0.0083)^{* * *}$ & $(0.0127)^{* *}$ \\
& 0.0000 & -0.0219 & 0.1646 & -0.1078 \\
Melbourne & -0.0281 & $(0.1655)$ & $(0.0402)^{* *}$ & $(0.5375)$ \\
Perth & -0.0126 & -0.1858 & -0.2378 \\
& & $(0.5445)$ & $(0.0799)^{* *}$ & $(0.1413)$ \\
Sydney & -0.0422 & -0.0352 & 0.5082 & -0.1478 \\
& & $(0.0005)^{* *}$ & $(0.5794)$ & $(0.3124)$ \\
\hline
\end{tabular}

Note: the numbers in the brackets are the p-values of the t-statistics with the null hypothesis that the coefficient is equal $0 .{ }^{* *}$ and $*$ denote the t-statistics are significant at the $5 \%$ and $10 \%$ critical levels respectively.

\subsection{House price convergence in Australian capital cities}

The estimates of the demographical spatial model based on the information from Australia were reported in Table 4 . The model assumes that Sydney was viewed as a dominant city, in influencing house price movements across the Australian capital cities. The house price level was also assumed to converge to steady ratio against the level of Sydney through distinct paths. The adjusted $\mathrm{R}$-square of the estimated model is $31 \%$, indicating that the model clearly explains the house prices across the Australian capital cities. The steady ratios of cities against the house price levels of Sydney are indicated by the estimates of $\alpha_{i}$. The negative and significant estimates of $\beta_{i}$ indicate that the house price levels in the corresponding city have a long run equilibrium relationship with the house price level in Sydney. The temporal effects on house prices were captured by the estimates of $\rho_{i}$, while the demographical spatial effects were indicated by the estimates of $\gamma_{i}$. The estimates of $\alpha_{i}$ varied from -0.0422 to 0.0035 across the capital cities of Australia. The estimate of $\alpha$ of Sydney indicates the steady state of the house price level, while the estimates of $\alpha_{i}$ of the other cities imply the long run relationship between the house price levels in the corresponding cities and the level in Sydney. Positive $\alpha_{i}$ were observed in Darwin and Hobart, while negative estimates were found in Adelaide, Brisbane, Canberra, Melbourne, Perth and Sydney.

The estimates of $\beta_{i}$ were negative but different in all the capital cities, except in Sydney. This indicates that the house price levels in the Australian capital cities converge towards to the house price level in Sydney; however the house price level in Sydney could not reach a steady state. The convergence speeds of the house prices in the capital city were distinct from each other according to the estimates of $\beta_{i}$. The absolute value of $\beta_{i}$ in Canberra was the largest followed by the values in Brisbane, Perth and Adelaide. This in- 
dicates that the house price level in Canberra should converge to the steady ratio against the house price level in Sydney more quickly than the house price levels in Brisbane, Perth and Adelaide. The insignificant estimates of $\beta_{i}$ in Darwin, Hobart and Melbourne indicated the house price different ratio convergences could not be confirmed based on the information applied in this research.

Moreover, the significances of the estimated $\beta_{i}$ appeared various. Specifically, the house price levels in Canberra, Brisbane and Perth converge to the price level in Sydney significantly, while the house price level in Adelaide converges at a relatively weaker degree. The converging relationships between the house price levels in Melbourne, Hobart and Darwin and that in Sydney are insignificant. The various convergence statuses are driven by the differences of the demographical structures, based on which the spatial autocorrelations of the house price levels in the Australian capital cities are negative. In other words, the house price level in a city, whose demographical structure is more different from that in Sydney, is more likely to converge to the house price level in Sydney. Therefore, the convergence relationships are significant in Canberra, Brisbane and Perth, where the demographical structures are distinct from Sydney, while the house prices in Melbourne and Hobart, with relatively similar demographical structures as Sydney, do not move together with the house price level in Sydney. The house price in Adelaide converges to the house price in Sydney with a weaker significance because of the modest degree of the demography-structure difference between Adelaide and Sydney. However, the insignificant convergence relationship between the house price levels in Darwin and Sydney is not caused by the demographical structure. Instead, the special housing system and policy in Darwin would account for the major factor that drives the house price in Darwin away from Sydney.

The temporal effects were illustrated by the estimates of $\rho_{i}$. The movements of the house price levels in Sydney were significantly influ- enced by its previous behaviours. A one-unit increase in the previous movements of house price level in the previous period led to an elasticity of 0.2462 in the increase. The estimates of $\rho_{i}$ were positive for all the other cities, except Melbourne. In Adelaide, Brisbane, Canberra, Darwin, Hobart and Perth, the house price different ratios between the house price levels of Sydney and one of the cities in the previous time period will enhances the spreads. However, the temporal effects of the previous spreads between Melbourne and Sydney reduced the house price differences. The demographical spatial effects of the neighbouring house price levels were indicated by the estimates of $\gamma_{i}$. The house price movements in Sydney were influenced significantly by the demographical spatial effects generated from the house price movements in other capital cities. A significant demographical spatial effect was observed in Darwin, which demonstrates that the spatial effect contributes to the house price level in Darwin diverging from that in Sydney. Alternatively, insignificant spatial effects on the house prices were found in the other capital cities. This indicates that the spatial effects cannot drive the house prices in other capital cities converging to that in Sydney in a short run.

\subsection{Predicting house price levels in Australian capital cities}

This research employed a generalised impulse response function based on the spatio-temporal model, described above, assuming a one-unit increase happened to the house price level in Sydney in period 0 . The responses of the house price levels in the Australian capital cities to the initial shock were calculated in a predicted period of 48 quarters. The results were plotted and reported in Figure 2.

It was observed that the house price levels in all the capital cities kept decreasing during the observation period, except for a slight increase in Perth in the first 5 quarters. The price level in Sydney was higher than the house price levels in the other capital cities over the first half of the predicted period. The 


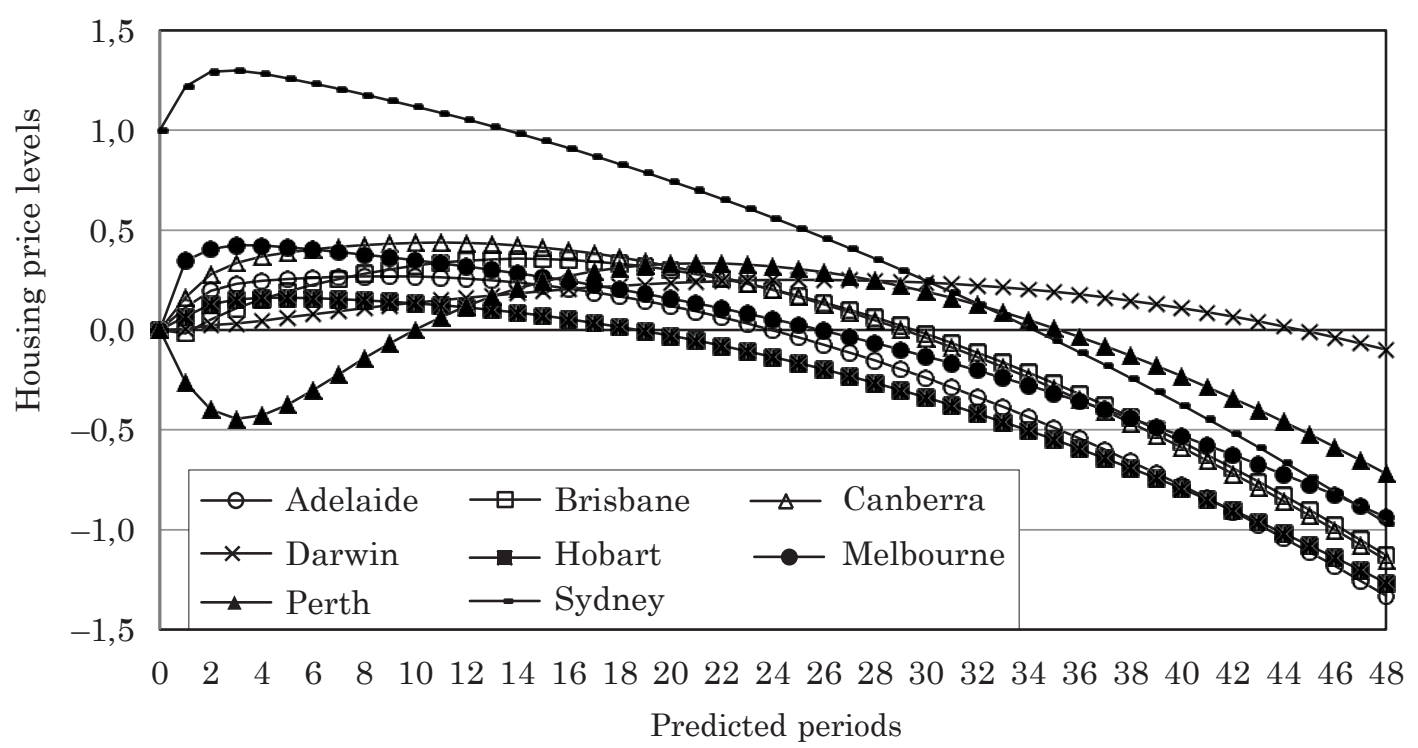

Figure 2. Predicted house price levels after a one-unit shock in Sydney house price

house price levels in Perth and Darwin caught up and exceeded the house price level in Sydney during the last part of the predicted period. The different ratios of the house price levels in Sydney and in the other cities decreased with time and moved towards steady ratios. However, the steady ratios and the time when the steady ratios were reached were different from one capital city to another. The results confirmed the house price levels in Canberra, Perth and Brisbane researched the steady ratios with Sydney sooner than the house price levels in other capital cities. It took about 30 quarters for Canberra to reach the steady ratios, while around 35 quarters were taken for Perth and Brisbane. A much longer time was needed for Darwin and Melbourne to reach the steady ratios.

It can be demonstrated that the house price levels in Australian capital cities converge to certain steady ratios against the house price level in Sydney in the long run at different speeds. In other words, the house price levels in the Australian capital cities will move towards their own steady states, where the house price levels in the other capital cities will move together with the movement of house price level in Sydney. The results also indicated that the steady states for the house price levels were determined by the regional effects. The regional effects, such as local demographical structures, developments of housing markets, economies, and so forth, vary across the Australian capital cities. Therefore, the house price levels in each capital city will have their own steady state, suggesting that the house price levels in the Australian capital cities will not be the same in the long run. In addition, although the temporal effects and spatial effects on house price levels were different across the capital cities, the convergences of house price levels were detected in every capital city, when the house price level in Sydney was selected as a benchmark. This implies that these convergences are a long-run property existing among the house price levels in the Australian capital cities.

In addition, the movements of the simulated house price levels were calculated and reported in Figure 3. 


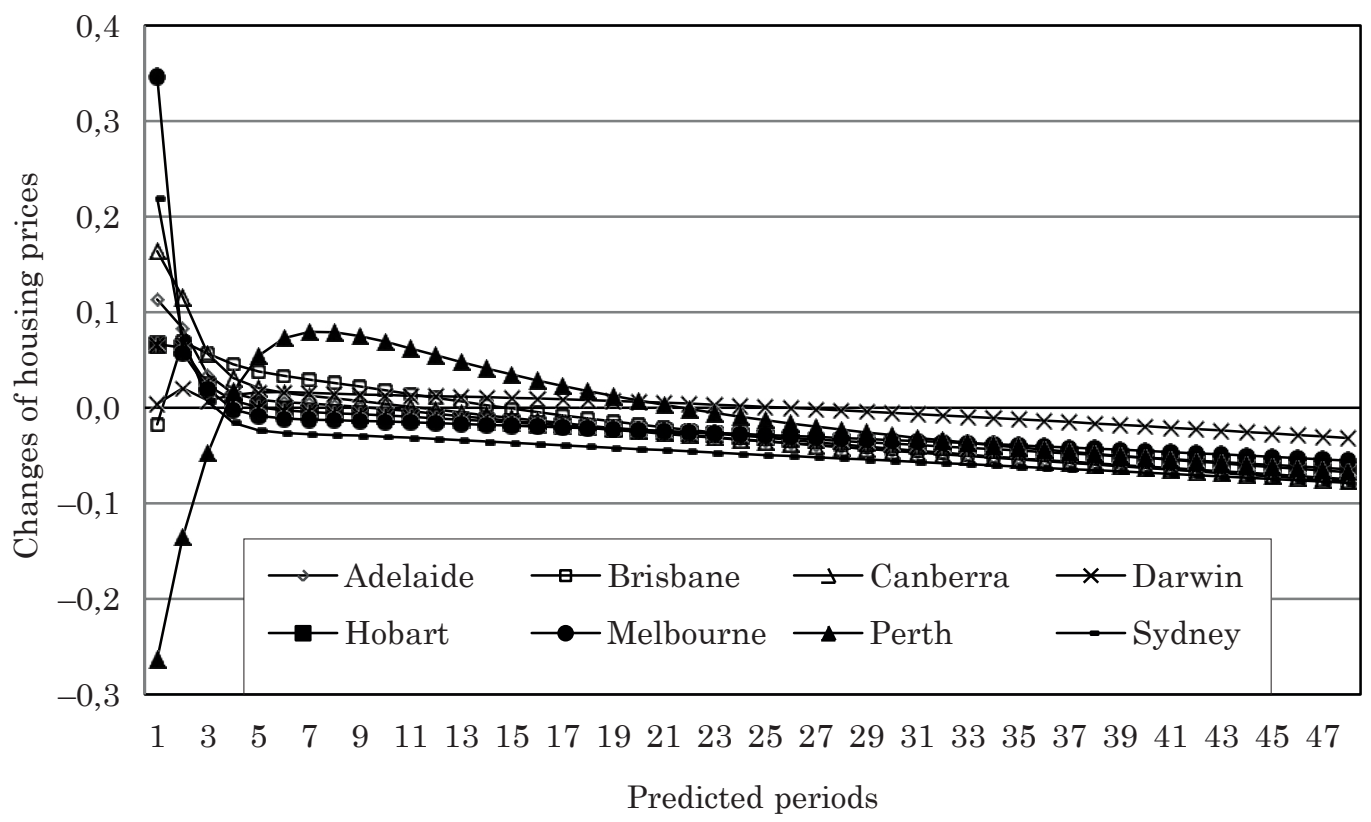

Figure 3. Movements of house price levels caused by a shock in Sydney

When an initial shock occurred in the house price level in Sydney, the house price movements in Adelaide, Canberra, Hobart, and Melbourne increased in the first predicted period, with decreases in the house price movements in Perth and Brisbane. The degrees of these increases dropped down quickly in the following quarters and became constant. The oneunit shock led to 0.35 increase in Melbourne in the first quarter observed, followed by 0.22 in Sydney, 0.16 in Canberra, 0.11 in Adelaide and 0.07 in Hobart, indicating the close demographical spatial relationships between house price movements in Sydney and in Melbourne and Canberra, which could not be reflected by the estimated spatio-temporal model. It also confirms that decreases occurred in the house price movements in Perth and Brisbane during the early quarters under observation. A decrease of 0.26 in the house price movement in Perth demonstrated a robust negative relationship between the movements in Perth and Sydney at the beginning.

In the short run, either or both the temporal and spatial factors bring significant impacts on the house price level different ratios in the Australian capital cities. The positive temporal effect elasticity and negative spatial effect elasticity found in Darwin, Hobart and Perth determine the large different ratios between the house price levels in these cities and the house price level in Sydney at the beginning periods after the initial shock. Since Perth has the largest temporal effect elasticity, fourth largest degree of spatial effect elasticity and relatively shorter demographical distance from Sydney, the different ratio between the house price levels in Perth and Sydney was dramatically large. Therefore, negative response or opposite movement emerged in the house price level in Perth. The positive temporal effect and spatial effect elasticity were found in Adelaide, Brisbane and Canberra, while negative temporal effect and spatial effect elasticity were found in Melbourne. Either the positive spatial effect elasticity or the negative temporal effect elasticity decreases the different ratios against the house price level in Sydney. Thus, the responses in these four cities were higher in the beginning period after the initial shock. 
In the long run, the effects of a one-unit shock in the house price movement in Sydney on the other house prices do not shrink to 0 . The initial shock in the house price in Sydney causes the house prices in other cities move towards or away from the house price level in Sydney. The house price movements in other cities will impact back on the house price in Sydney via the demographical spatial spilliovers, since the house price in Sydney is significantly influenced by the demographical spatial effects. Although the movements of house prices are permanent, the differences between the house price in Sydney and those in Adelaide, Brisbane, Canberra and Perth are decreasing. On the other hand, the house prices in Darwin, Hobart and Melbourne diverges from the house price in Sydney.

\section{CONCLUSIONS}

This research developed a spatio-temporal model to investigate the convergence of house price ratios. Instead of using geographic distance, this research implemented the demographic structures and developing scales of housing markets to construct spatial weights. The newly developed spatio-temporal model was subsequently applied to investigate the convergence of house prices in the Australian capital cities. Generalised impulse response functions based on the demographical spatial model were also adopted to simulate the activities of house price levels. The conclusions generated were as follows:

First, the house price levels were confirmed to be spatially correlated in the Australian capital cities, based on the demographical distances. Secondly, the estimates of the spatiotemporal model indicated the house price levels in Canberra, Brisbane and Perth converged to the house price level in Sydney. Weaker convergence of house price different ratio against Sydney was observed in Adelaide, while uncertainty remained in the house price levels in Darwin, Hobart and Melbourne. The results of the impulse responses confirmed that the highest convergence speed was in Canberra, followed by Brisbane and Perth. Finally, the house price levels in Brisbane, Darwin, Hobart and Sydney were significantly affected by their own previous behaviours, while the house price levels in Darwin and Sydney were significantly influenced by the house price movements in other capital cities.

\section{REFERENCES}

ABS (2011a) Australian demographic statistics. Cat no. 3101.0. Australian Bureau of Statistics, Canberra.

ABS (2011b) Building approvals. Cat no. 8731.0. Australian Bureau of Statistics, Canberra.

Anselin, L. (1988) Spatial econometrics: methods and models. Dordrecht: Kluwer Academic Publishers incorporates.

Azomahou, T., Diebolt, C. and Mishra, T. (2009) Spatial persistence of demographic shocks and economic growth, Journal of Macroeconomics, 31(1), pp. 98 127. http://dx.doi.org/10.1016/j.jmacro.2007.08.013

Beenstock, M. and Felsenstein, D. (2007) Spatial vector autoregressions, Spatial Economic Analysis, 2(2), pp. 167-196. http://dx.doi. org/10.1080/17421770701346689

Bourassa, S. C. and Hendershott, P. H. (1995) Australian capital city real house prices, 1979-1993, Australian Economic Review, 28(3), pp. 16-26. http://dx.doi. org/10.1111/j.1467-8462.1995.tb00990.x

Clauretie, T. M. and Daneshvary, N. (2009) Estimating the house foreclosure discount corrected for spatial price interdependence and endogeneity of marketing time, Real Estate Economics, 37(1), pp. 43-67. http:// dx.doi.org/10.1111/j.1540-6229.2009.00234.x

Conley, T. G. (1999) GMM estimation with cross sectional dependence, Journal of Econometrics, 92(1), pp. 1-45. http://dx.doi.org/10.1016/S0304-4076(98)00084-0

Cook, S. (2003) The convergence of regional house prices in the UK, Urban Studies, 40(11), pp. 2285-2294. http://dx.doi.org/10.1080/0042098032000123295

Drake, L. (1995) Testing for convergence between UK regional house prices, Regional Studies, 29(4), pp. 357-366. http://dx.doi.org/10.1080/00343409512 331349023

Elhorst, J. P. (2003) Specification and estimation of spatial panel data models, International Regional Science Review, 26(3), pp. 244-268. http://dx.doi.org/10.1177/0160017603253791

Greene, W. H. (2002) Econometric analysis. New Jersey: Pearson Education, Inc.

Holly, S., Hashem Pesaran, M. and Yamagata, T. (2011) The spatial and temporal diffusion of house prices in the UK, Journal of Urban Economics, 69(1), pp. 2-23. http://dx.doi.org/10.1016/j.jue.2010.08.002 
Holmes, M. J. (2007) How convergent are regional house prices in the United Kingdom? Some new evidence from panel data unit root testing, Journal of Economic and Social Research, 9(1), pp. 1-17.

Holmes, M. J. and Grimes, A. (2008) Is there long-run convergence among regional house prices in the UK?, Urban Studies, 45(8), pp. 1531-1544. http://dx.doi. org/10.1177/0042098008091489

Krugman, P. (2011) The new economic geographiy, now middle-aged, Regional Studies, 45(1), pp. 1-7. http:// dx.doi.org/10.1080/00343404.2011.537127

Liu, C., Luo, Z., Ma, L. and Picken, D. (2008) Identifying house price diffusion patterns among Australian state capital cities, International Journal of Strategic Property Management, 12(4), pp. 237-250. http:// dx.doi.org/10.3846/1648-715X.2008.12.237-250

MacDonald, R. and Taylor, M. P. (1993) Regional house prices in Britain: long-run relationships and short-run dynamics, Scottish Journal of Political Economy, 40(1), pp. 43-55. http://dx.doi. org/10.1111/j.1467-9485.1993.tb00636.x

Meen, G. (1996) Spatial aggregation, spatial dependence and predictability in the UK housing market,
Housing Studies, 11(3), pp. 345-372. http://dx.doi. org/10.1080/02673039608720862

Pesaran, M. H., Schuermann, T. and Weiner, S. M. (2004) Modeling regional interdependencies using a global error-correcting macroeconometric model, Journal of Business \& Economic Statistics, 22(2), pp. 129-162. http://dx.doi.org/10.1198/073500104000000019

Pesaran, M. H. and Shin, Y. (1998) Generalized impulse response analysis in linear multivariate models, Economics Letters, 58(1), pp. 17-29. http://dx.doi. org/10.1016/S0165-1765(97)00214-0

Poterba, J. M., Weil, D. N. and Shiller, R. (1991) House price dynamics: the role of tax policy and demography, Brookings Papers on Economic Activity, 1991(2), pp. 143-203.

Quercia, R. G., McCarthy, G. W., Ryznar, R. M. and Talen, A. C. (2000) Spatio-temporal measurement of house price appreciation in underserved areas, Journal of Housing Research, 11(1), pp. 1-28.

Rodda, D. T. and Patrabansh, S. (2007) Homeowner age and house price appreciation, Cityscape: a Journal of Policy Development and Research, 9(3), pp. 123-152. 